PABLO BEYTÍA REYES, CARLOS CRUZ INFANTE

\title{
Digital Pathways, Pandemic Trajectories
}

Using Google Trends to Track Social Responses to COVID-19 


\section{ABSTRACT}

We already know which countries have controlled the spread of COVID-19 better and what "good practices" have enabled them to do so. Eventually, some of these policies could be replicated in other countries. But it is not enough to make a well-informed public intervention. We also need quickly available indicators of how actively populations are responding to the virus threat because current changes in social behaviour could mean significant differences in the spread of the COVID-19 in two weeks (after the incubation period). In this article, Pablo Beytía Reyes and Carlos Cruz Infante explore the potential of Google Trends to quickly track social responses to the pandemic. In all the countries that have reached a downward changepoint in the COVID-19 contagion, an "information saturation peak" preceded it: people were massively searching for information on the subject over 2 to 5 days, and about a week after the peak of searches was reached, a decline in the growth trend of coronavirus confirmed cases could be observed. Does it make sense to associate a Google search boom with a decrease in transmission trends? The authors propose that the frequency of searches is a quick indicator of 1) people' concerns on the virus, 2) the development of a more informed citizenry on how to avoid transmission and 3) active social response to the virus spread, which generally lead to a downward change in the contagion trend.

\section{KEYWORDS}

COVID-19, coronavirus, epidemic, crisis management, digital trace analysis, social indicators, digital methods, public policy, healthcare policy

\section{ABOUT THE AUTHORS}

Pablo Beytía Reyes is a research fellow at HIIG's Knowledge \& Society research programme, as well as a $\mathrm{PhD}$ candidate at the Department of Social Sciences of Humboldt University of Berlin, and a scholarship holder of the German Academic Exchange Service (DAAD) and the Chilean Commission for Science and Technology (CONICYT). His research has focused on the digital sociology of knowledge, social theory and social development.

Carlos Cruz Infante is a sociologist with an MBA and is former chief of strategic content of the General Secretariat of the Presidency of the Chilean Government. He now works as a consultant and independent researcher. He has given lectures in Italy about the MERCOSUR-European Union FTA, as well as about Latin America's turmoil in 2019, and has advised the Inter-American Development Bank (IADB). 


\section{CONTENTS}

\section{INTRODUCTION}

1.1 A big problem: the invisibility of symptoms and the urgency of rapid social monitoring

1.2 The potential of digital methods and Google Trends

1.3 Hypothesis and paper structure

2 METHODS

3.1 From whom we can learn: recovering countries 


\section{INTRODUCTION}

\subsection{A big problem: the invisibility of symptoms and the urgency of rapid social monitoring}

The spread of COVID-19 or coronavirus has been controlled to a greater or lesser degree in different countries. For example, China, South Korea, Singapore (at an early stage) - and more recently Denmark, Sweden, and Norway - have shown signs of containing the dissemination of the virus, which has certainly not happened in Italy, Iran, or Spain. With this level of variability, a careful analysis of successful countries is necessary, as this enables policymakers to identify good healthcare policy practices and eventually replicate them elsewhere.

However, it is not enough to react properly. Since the incubation period for the virus (the pre-symptomatic period) ranges between 2 and 14 days $^{1}$, infection figures will always serve as a late warning to policymakers about the effectiveness of their actions and public recommendations. And if they choose the wrong policies, the results will be disastrous two weeks later. This makes it essential to combine appropriate policies with expeditious indicators of the social response to this epidemic. In times of COVID-19, response time is crucial.

But how can we observe these social responses in an agile and viable way? Perhaps not by surveying a population that is already stressed out trying to solve everyday problems. We should also disregard any research method that involves human contact immediately to avoid further spreading of the contagion. And of course all methods of direct observation - whether or not they involve social interaction - can be inappropriate, as many countries have opted for quarantine or mass confinement of the population, which would make direct observation of social behaviour very difficult.

\subsection{The potential of digital methods and Google Trends}

In this strange situation, a more promising, viable and efficient option seems to be analysing people's digital behaviour. While it is true that not everyone uses the Internet daily, we believe that it is currently possible to assume that 1) a significant proportion of the population leaves digital traces of their daily behaviour, 2) this proportion may have increased in recent days, which have been characterised by high rates of confinement within households, and 3) changes in these digital traces may reflect, to some extent, general behavioural changes in a population.

If these assumptions are correct, then it would seem reasonable to use digital trace analysis as a way to quickly monitor people's responses regarding the coronavirus. This idea, although it might seem unconventional, has its roots in a vast scientific literature of recent years, where different disciplines have collaborated to develop "digital methods" digital humanities, but also in emerging sub-disciplines of the social sciences such as digital sociology ${ }^{3}$, digital anthropology ${ }^{4}$ and digital geography ${ }^{5}$.

\footnotetext{
${ }^{1}$ Lai, C. C., Shih, T. P., Ko, W. C., Tang, H. J., \& Hsueh, P. R. (2020). Severe Acute Respiratory Syndrome Coronavirus 2 (SARS-CoV-2) and Coronavirus Disease-2019 (COVID-19): the Epidemic and the Challenges. International Journal of Antimicrobial Agents, 105924.

2 Rieder, B, Röhle, T (2012) Digital Methods: Five Challenges. In: Berry, DM (ed.) Understanding Digital Humanities. London: Palgrave Macmillan, pp. 67-84. Rogers, R. (2013). Digital Methods. London: MIT Press. Venturini, T., Bounegru, L., Gray, J., \& Rogers, R. (2018). A Reality Check (list) for Digital Methods. New Media \& Society 20(11), 4195-4217.

${ }^{3}$ Lupton, D. (2014). Digital Sociology. Routledge. Marres, N. (2017). Digital Sociology: The Reinvention of Social Research. John Wiley \& Sons.

${ }^{4}$ Miller, D. \& Slater, D. (2000). The Internet: an Ethnographic Approach. Oxford: Berg. Horst, H. A., \& Miller, D. (Eds.). (2013). Digital anthropology. A\&C Black.

${ }^{5}$ Zook, M., Dodge, M., Aoyama, Y., \& Townsend, A. (2004). New Digital Geographies: Information, Communication, and Place. In
} 
In line with this emergent literature, this article aims to assess whether it is possible to associate digital traces with population responses to COVID-19. Specifically, we will evaluate the usefulness of looking at Google searches when studying social-group responses to this epidemic.

But why Google searches? The first reason is that this search engine is widely used: it is the most visited website in the world ${ }^{6}$, with more than 3.5 billion daily searches for information ${ }^{7}$ and with a share of more than $92 \%$ of the global search engine market ${ }^{8}$. This widespread use suggests enormous potential for understanding changes in the aggregate interests of large populations. The second reason is that Google search trends have proven to be useful in observing people's concerns and in predicting social, economic, and public health patterns ${ }^{9}$. In recent years, for example, this information has been used to predict phenomena as diverse as housing prices, financial markets, unemployment rates, travel destinations, political elections, and the dissemination of cryptocurrencies ${ }^{10}$. But more importantly in this case: it has been widely used to monitor infectious diseases - especially flu and influenza epidemics - in various places of the world ${ }^{11}$.

\subsection{Hypothesis and paper structure}

Considering the potential of this information source, we hypothesise that the increase in the frequency of searches on the coronavirus in a specific country reflects an increase in people's concern and interest regarding the epidemic and also greater dissemination of knowledge about the virus symptoms and its forms of containment. This would result in a stronger response of the population against the contagion. Thus, a substantial increase in searches on coronavirus could indicate a social advance in the containment of the virus.

This hypothesis will be examined in a few steps. In a first section (2), we will explain the methods that will allow us to examine, in different countries, the trends in COVID-19 contagion, the relevant points of change in these trends, and the frequencies of Google searches on the coronavirus. We will then devote a part (3) to analysing the patterns of transmission (confirmed cases) and information dissemination shown by these countries. At this stage, we will address two relevant issues: the evolution of the "recovering countries" (3.1), and the current situation of some "in-process countries" (3.2). In the fourth section, we will evaluate the mechanism that links Google searches and a downward shift in the transmission rate - based on evidence from the Chilean case (4.1) -

Geography and Technology (pp. 155-176). Springer, Dordrecht. Graham, M. (2014). Internet Geographies: Data shadows and digital Divisions of Labour. In Society and the Internet: How Networks of Information and Communication are Changing our Lives, eds M. Graham and W. H. Dutton. Oxford: Oxford University Press. 99-116.

${ }^{6}$ Alexa Internet (2020). The Top 500 Sites on the Web. Available at https://www.alexa.com/topsites

${ }^{7}$ Internet live Stats (2020). Available at https://www.Internetlivestats.com/google-search-statistics/

${ }^{8}$ Stat Counter (2020). Available at https://gs.statcounter.com/search-engine-market-share

9 Hubbard, D. W. (2011). Pulse: The New Science of Harnessing Internet Buzz to Track Threats and Opportunities. John Wiley \& Sons.

${ }^{10}$ Choi, H., \& Varian, H. (2012). Predicting the Present with Google Trends. Economic record, 88, 2-9. Polykalas, S. E., Prezerakos, G. N., \& Konidaris, A. (2013, December). An Algorithm based on Google Trends' Data for Future Prediction. Case study: German Elections. IEEE International Symposium on Signal Processing and Information Technology (pp. 000069-000073). IEEE. Wu, L., \& Brynjolfsson, E. (2015). The Future of Prediction: How Google Searches Foreshadow Housing Prices and Sales. Economic analysis of the digital economy (pp. 89-118). University of Chicago Press. Matta, M., Lunesu, I., \& Marchesi, M. (2015, June). Bitcoin Spread Prediction Using Social and Web Search Media. In UMAP Workshops (pp. 1-10). Ahmed, F., Asif, R., Hina, S., \& Muzammil, M. (2017). Financial Market Prediction Using Google Trends. International Journal of Advanced Computer Science and Applications, 8(7), 388-391.

11 Dukic, V., Lopes, H. F., \& Polson, N. G. (2012). Tracking Epidemics with Google Flu Trends Data and a State-space SEIR Model. Journal of the American Statistical Association, 107(500), 1410-1426. Pollett, S., Boscardin, W. J., Azziz-Baumgartner, E., Tinoco, Y. O., Soto, G., Romero, C., ... \& Rutherford, G. W. (2016). Evaluating Google Flu Trends in Latin America: Important Lessons for the Next Phase of Digital Disease Detection. Clinical Infectious Diseases, Volume 64, Issue 1, 1 January 2017, Pages 34-41. Seo, D. W., \& Shin, S. Y. (2017). Methods using Social Media and Search Queries to Predict Infectious Disease Outbreaks. Healthcare Informatics Research, 23(4), 343-348. Yang, S., Santillana, M., Brownstein, J. S., Gray, J., Richardson, S., \& Kou, S. C. (2017). Using Electronic Health Records and Internet Search Information for Accurate Influenza Forecasting. BMC Infectious Diseases, 17(1), 332. Xu, Q., Gel, Y. R., Ramirez, L. L. R., Nezafati, K., Zhang, Q., \& Tsui, K. L. (2017). Forecasting Influenza in Hong Kong with Google Search Queries and Statistical Model Fusion. PloS one, 12(5). Lu, Y., Wang, S., Wang, J., Zhou, G., Zhang, Q., Zhou, X., ... \& Chou, K. C. (2019). An Epidemic Avian Influenza Prediction Model Based on Google Trends. Letters in Organic Chemistry, 16(4), 303-310. 
and look at the importance of the content that is communicated in times of massive information searches on the Internet, reviewing the Italian case (4.2). Finally, the main conclusions of this study will be summarised in the last section (5), which will also discuss the strengths and limits of this research.

\section{METHODS}

This study is of an exploratory nature, i.e. it is intended to increase familiarity with a hitherto unknown phenomenon - the association between Internet searches on Google and the spread of COVID-19 infection across countries. The aim of this exercise is to find relevant patterns and pave the way for future systematic research on the issue. For the latter, we will also seek to develop some explanatory hypotheses about the relationships studied.

The methodology we use can be divided into three stages. First, we analysed the evolution of confirmed COVID19 cases in fourteen countries: China, Singapore, South Korea, Denmark, Sweden, Norway, Italy, Spain, Germany, the United States, Mexico, Brazil, Argentina and Chile. These countries were chosen because they allow us to obtain a sample with 1) relevant cases in the global development of the epidemic, 2) high diversity geographical, demographic, cultural and political - and 3) information on outbreaks of the virus in different periods of time. Information on confirmed COVID-19 cases in these countries was extracted from the "2019 Novel Coronavirus COVID-19 (2019-nCoV) Data Repository,"12 provided by Johns Hopkins University Center for Systems Science and Engineering (JHU CSSE).

Since our goal is to understand the relationship between Internet searches and containment of the epidemic, we grouped these case studies into two broad categories. The first one, which we have called "recovering countries", includes those nations where the exponential trend in the spread of the virus has already shifted downwards, exhibiting some pandemic control signs. In contrast, the category "in-process countries" comprises the cases where the exponential spreading has not decreased substantially. We are interested in observing both groups since the associations found in the former can be useful to make projections about virus containment in the latter.

In the second step, trend breaks (upwards and downwards) in the spread of the virus were estimated. For this, we used "changepoint analysis", a technique that allows us to detect the points at which the statistical properties of a sequence of observations change significantly. The points of change are computed by 1) considering a statistical measure - either mean, variance or both - 2) selecting an algorithm or search method (AMOC, PELT, SegNeigh or BinSeg), and 3) establishing sensitivity parameters for the tests. In this case, we mainly (but not only) observed the changes in the variance of the confirmed COVID-19 cases that have been accumulating in the countries. For all tests, the PELT method was used to identify the breakpoints in the trends. However, we did not use a fixed sensitivity parameter: for each country, we performed multiple tests with different levels of sensitivity, which allowed us to distinguish the most consistent or persistent points of change.

The third stage of the methodology included the analysis of Google search frequencies for coronavirus. We used Google Trends ${ }^{13}$ to extract these data. For each country, we tracked the search frequencies on the word "coronavirus" in the last 90 days. We later contrasted this information with the figures for the spread of the virus in each country.

Afterwards, we complemented the trend analysis with more detailed information on the Chilean and Italian cases. These countries were selected because they provide us with valuable information to further understand the mechanism that links Google searches and social responses to COVID-19.

\footnotetext{
${ }^{12}$ Available at https://github.com/CSSEGISandData/COVID-19

${ }^{13}$ Available at https://trends.google.com/
} 


\section{SEARCH PEAKS AND POINTS OF CHANGE IN THE VIRUS' SPREAD}

\subsection{From whom we can learn: recovering countries}

As representatives of this category, we chose the cases of China, South Korea, Singapore (at least in its first stage), Norway, Sweden, and Denmark. When selecting these countries, we used various criteria, including a significant decline in the contagion increment but also the cultural and institutional diversity among them: there are both Asian and European countries with different ethnicities and cultures, as well as diverse political systems and public health policies.

The first cases were reported in Asia by the end of December 2019, and exponential contagion started in the first week of February. As Table 1 shows, China was able to halt the exponential transmission of the virus after 20 days; South Korea did so after eight days. Singapore's situation was a bit sui generis: they controlled the virus very fast (in about 10 days), even before its contagion rate went exponential, and then, after 19 days, a renewed wave of infection started (about March 5).

Concerning the North European countries, the number of officially reported cases raised significantly in the fourth week of February 2020. Sweden experienced a significant increase after March 4; they halted the trend after nine days. In Norway and Denmark, transmission management was also quite fast. The former started containment after 10 days and the latter did so in a breathtakingly short period of only two days.

Table 1: Changepoint dates of COVID-19 contagion and Google searches peak in the recovering countries

\begin{tabular}{|c|c|c|c|}
\hline Country & Upward changepoint & Google searches peak & Downward changepoint \\
\hline China & February 6 & January 26 & February 17 \\
\hline Singapore & February 3 & February 7 & February 13 \\
\hline South Korea & February 24 & February 23 & March 3 \\
\hline Sweden & March 4 & March 12 & March 13 \\
\hline Norway & March 5 & March 12 & March 15 \\
\hline Denmark & March 10 & March 11 & March 12 \\
\hline
\end{tabular}

Source: authors, based on Google Trends Analytics and coronavirus COVID-19 Global Cases by the Center for Systems Science and Engineering (CSSE) at Johns Hopkins University.

If we only consider the period between the beginning of the exponential disease contagion and the date in which each country started containing the spread, there is no clear pattern. However, if we instead use the time when Google searches related to the coronavirus peaked (100) in each country, we do find a relation with the date at which those countries achieved virus control.

On average, in these countries the downward turning point in the infection rate occurred after 7 days of the "information saturation peak" (Google searches); if we leave aside the very peculiar case of China, the figure is four days ${ }^{14}$.

\footnotetext{
${ }^{14}$ The Chinese situation has some peculiarities. First, it is the country where the first human subject got infected with COVID-19, and second, the Chinese specialists changed the testing method two weeks after the disease started spreading. Those facts add
} 
With respect to Asia, trends in COVID-19 spread changed 12 days after the information saturation peak on average. While China took 22 days to reach a downward changepoint after the contagion peak, South Korea took 8 days and Singapore took 6 days.

The North European cases were much faster. On average, those countries took 2.3 days to arrive at the transmission downward changepoint after they reached the peak of information saturation. Sweden took only 1 day, and both Norway and Denmark did it in 3 .

Figure 1. Evolution of COVID-19 confirmed cases, Google searches and downward changepoints in recovering countries

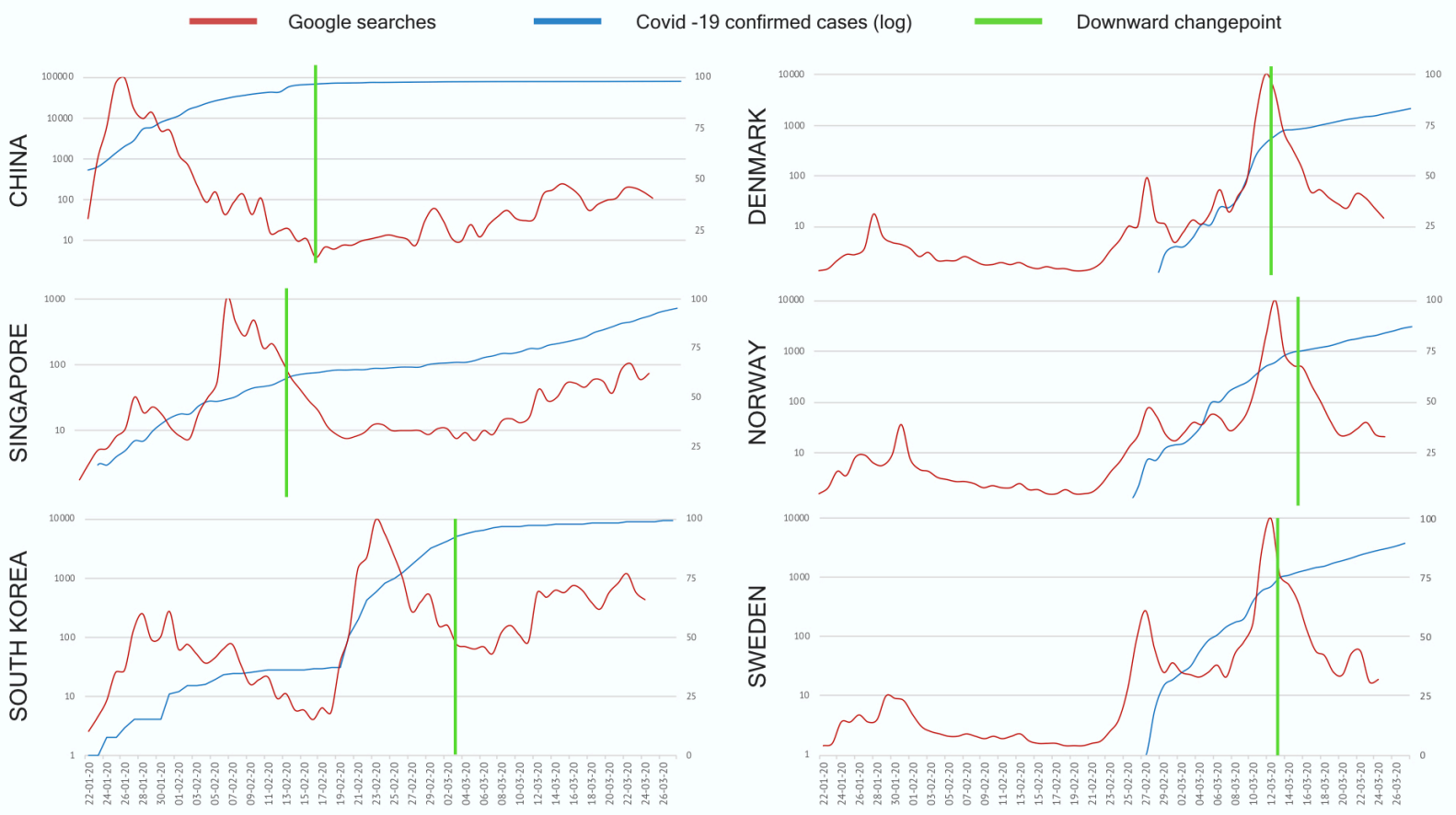

Source: authors, based on Google Trends Analytics and coronavirus COVID-19 Global Cases by the Center for Systems Science and Engineering (CSSE) at Johns Hopkins University.

As we see it, this finding is valuable in terms of crisis management. Even though the information saturation peak within a country or region might not be enough to predict how much time it will take to get the crisis under control, it might provide a clue about how actively involved the people are regarding that crisis, and therefore, we might expect them to adopt the measures needed to overcome it sooner or later. Despite the variable distance between the maximum number of searches on Google and the downward changepoint of contagion, we are certain that the former precedes the latter in any case and that the time for change seems to be quite short (one week on average).

\subsection{Those who could benefit from this: in-process countries}

While some countries have reached a downward changepoint, we can also find ones that are still struggling with it. This is the case for some Central European countries, such as Germany, Italy, and Spain, as well as the United States and others from Latin America, like Argentina, Brazil, Chile, and Mexico. The following graph portrays

complexity when making compared analysis with other countries, and therefore, do not allow us to assess easily both the contagion figures and the tipping points of that spreading. 
the contagion curve for each of those countries.

Figure 2. Evolution of confirmed cases of COVID-19, in-process countries (log)
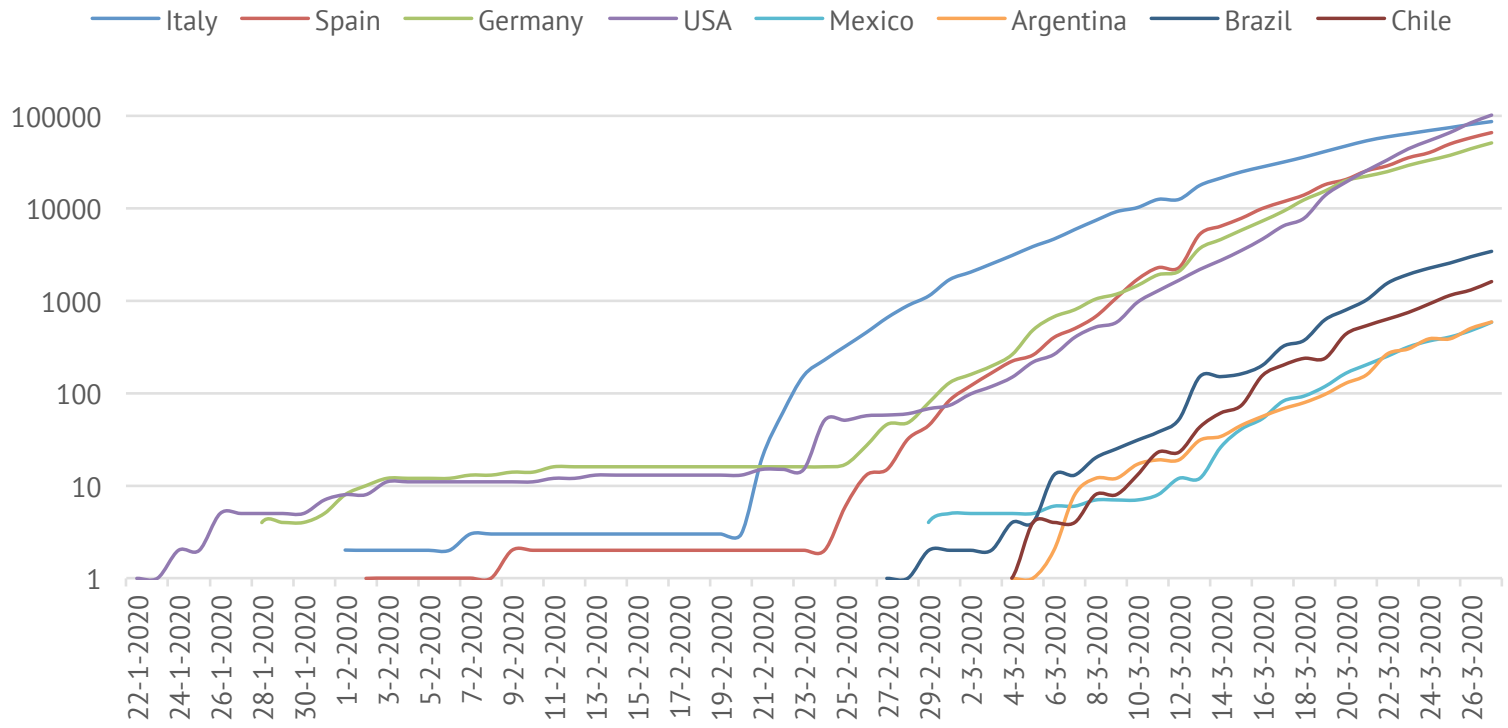

Source: authors, based on Coronavirus COVID-19 Global Cases by the Center for Systems Science and Engineering (CSSE) at Johns Hopkins University.

Considering that the recovering countries took 7 days on average to arrive at the downward changepoint of the infection after having reached the information saturation peak, we would expect to see a similar situation for the in-process countries. So, what about Google Trends regarding those countries? The figure below shows the searches on Google related to the coronavirus in those territories.

\section{Figure 3. Google searches related to COVID-19 in the in-process countries}

- Italy - Spain - Germany - USA - Mexico - Brazil — Argentina - Chile

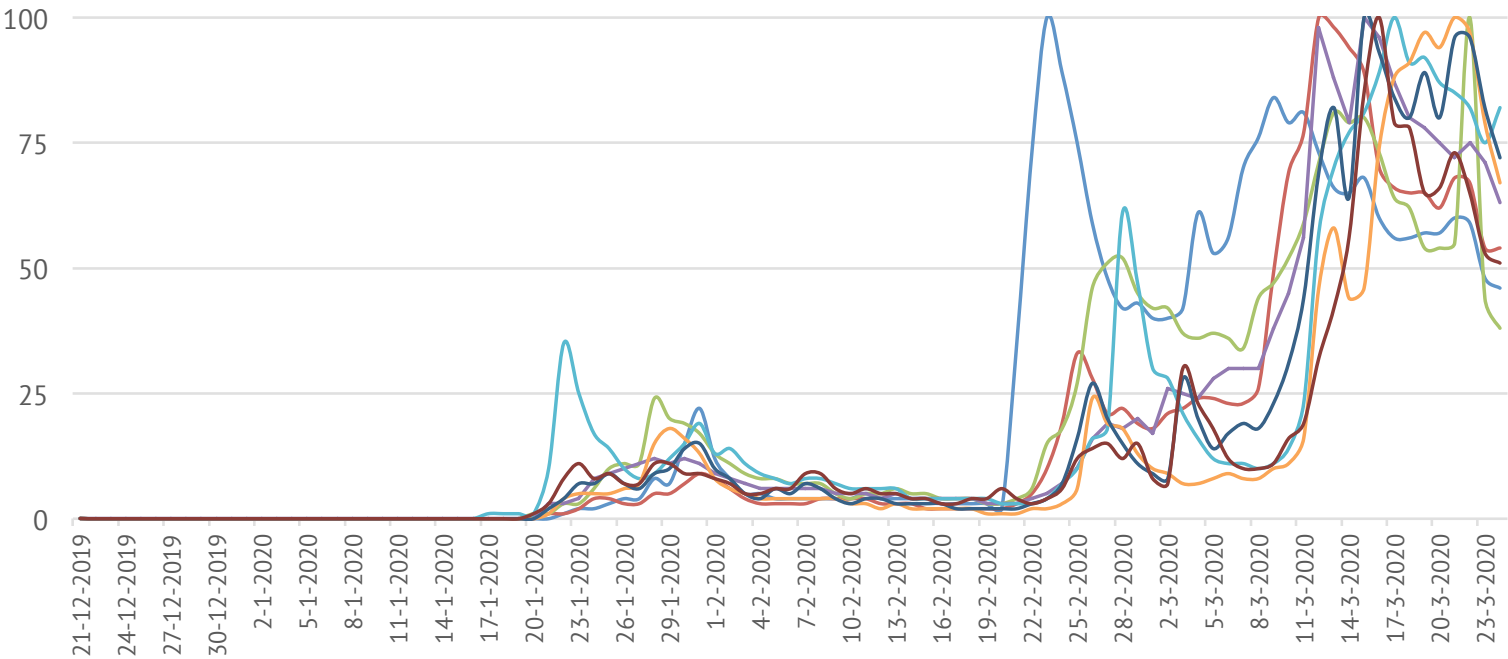

Source: authors, based on Google Trends Analytics.

Except for the case of Italy - which we will review in detail later - after March 12 the in-process countries began 
reaching their information saturation peak. Considering that, we tend to believe that at some point between March 19 and April 5, some of those countries will also reach a downward changepoint. But the agility and strength of that process, of course, depends on many political variables and on the way the citizenry responds in each country. In some cases, moreover, the information received may be highly confusing or contested, which could also diminish the effect of an information peak.

A good example of the latter could be found in Italy. But before reviewing that case, we will look more deeply into the mechanism that could explain the link between Google searches and the decrease in the spread of COVID-19.

\section{ANALYSIS FROM CASE STUDIES}

\subsection{The process linking searches and contagion: empirical evidence from the Chilean case}

It is important to examine the full mechanism that would be developing in the relationship we have found between an information peak and a downward shift in the contagion trend. In the introduction, we mentioned our hypothesis, which we now intend to justify in greater depth.

Figure 4 shows the theoretical mechanism that we propose to link peaks in Google searches to a decrease in the contagion trends:

Figure 4. The theoretical mechanism that links Google searches to a decrease in the contagion trend

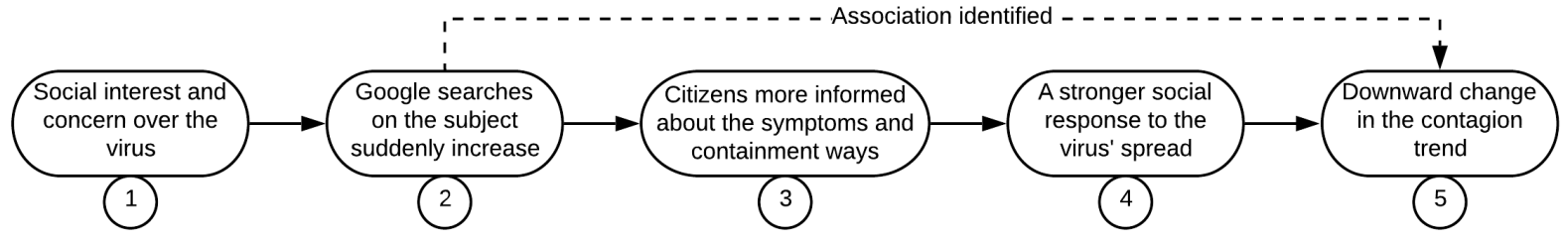

As can be seen, our model distinguishes five moments in a process that is almost instantaneous - despite the fact that its effects on infection figures may be up to two weeks delayed due to the incubation time. However, the information we have analysed so far only links two of these moments - the sudden increase in searches (moment 2 ) and the decrease in the contagion trend (moment 5). Our explanation hence implicitly assumes that moment 2 (Google searches) might be associated with the development of moments 1, 3 and 4, generating moment 5 (change in the contagion trend) as a joint result.

We have focused on the relationship between moments 2 and 5 because our main intention has been to evaluate the usefulness of Google searches as a fast and feasible indicator to monitor social responses in times of crisis. The whole process, in contrast, would be much more difficult and slower to observe. However, if we want to explain this relationship - and not only establish a more or less predictive association between both variables - it is necessary to examine whether there is an empirical link between step 2, on the one hand, and steps 1, 3 and 4 . Are the increases in Google searches effectively related to citizens' concerns (as a precedent) and to the emergence of more informed citizens who respond more strongly to the spread of the virus (as a consequence)?

This matter is very difficult to study empirically. While the information peaks in the countries examined have already occurred, data on their social behaviours cannot be collected simultaneously. Therefore, our only option is to find case studies where the appropriate data - information on social perceptions and behaviours against transmission in the period before and after the information saturation peak - have been collected coincidentally. 
This particular situation occurred in Chile, whose population was monitored in detail in two studies by the consultancy firm Activa Research ${ }^{15}$. These studies measured in two time periods the reported perceptions and behaviours of Chileans with respect to the coronavirus. What is interesting is that both measurements were made just before and after a very clear information saturation peak in Google searches, which allows for comparison of results and for defining what social responses were associated with this sudden search for information. Figure 5 shows the search frequencies in Chile and the two periods in which the public opinion surveys were conducted.

Figure 5. Google search evolution in Chile, and Activa Research's perception surveys

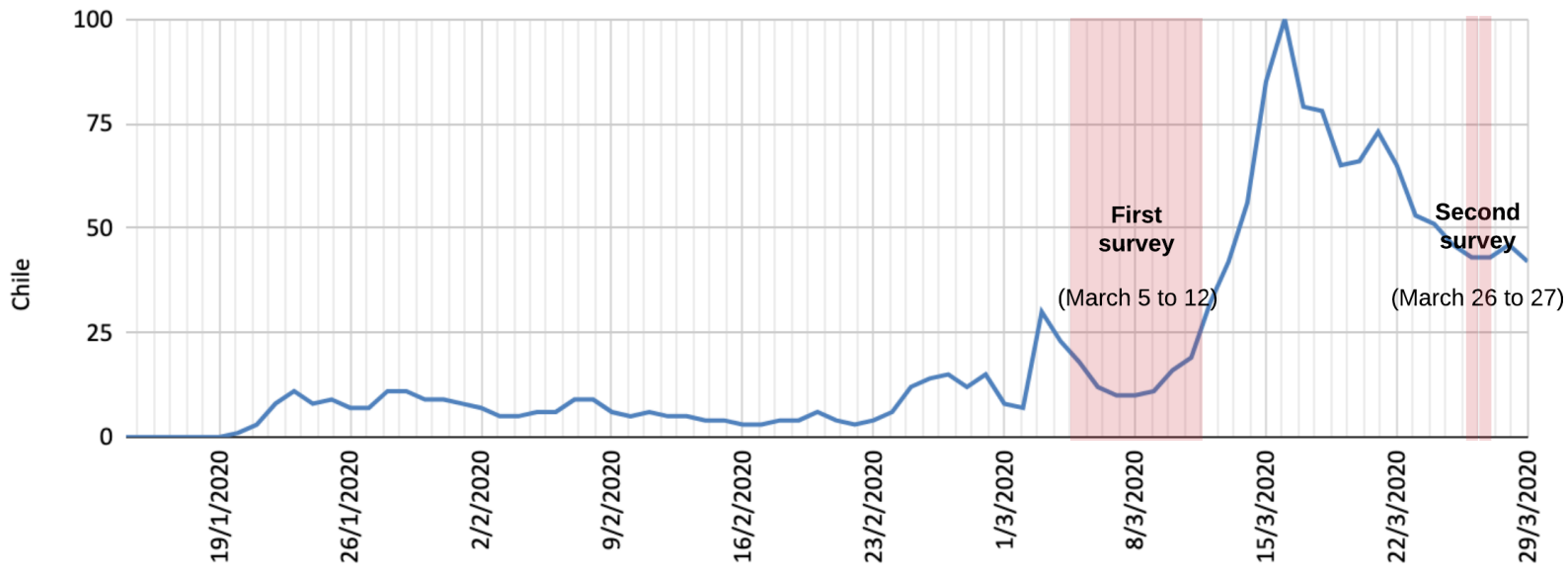

Source: Google Trends and Activa Research (2020)

When comparing the pre-peak and post-peak period, there are three relevant conclusions that can be drawn from these studies. First, there was a notable rise in citizen concern about the coronavirus: before the information peak, $37.3 \%$ of those surveyed said they were worried or very worried about the virus, while in the second period this percentage had risen to $87.5 \%$.

Second, more people began to be informed about how to prevent the virus. The percentage of informed or very informed respondents rose from $67.1 \%$ to $90.8 \%$. This progress was also mainly due to the growth in the number of highly informed people, which rose from $30.6 \%$ to $51.4 \%$.

Finally, there was notable dissemination of measures to prevent contagion. More people reported washing their hands frequently with soap, stopping kissing people or touching their hands, avoiding sneezing on hands, using alcohol gel, avoiding crowded places, wearing masks in public places, not touching nose or eyes without washing hands, and avoiding the consumption of uncooked animals.

This information on the change in prevention behaviour was also consistent with a major shift in spatial mobility patterns. In recent weeks, Google has published extraordinary reports on the displacement trends for people in different countries - obtained from Google Maps' information on "popular times" for visiting places ${ }^{16}$. In the report on Chile, a very clear trend can be seen: in the period when Google searches increased up until the information saturation peak - approximately between March 8 and 16 - mobility decreased in places of retail and recreation $(-73 \%)$, grocery and pharmacy $(-55 \%)$, parks $(-72 \%)$, transit stations $(-64 \%)$, and work $(-42 \%)$. On the other hand, mobility in places of residence increased $(+24 \%)^{17}$. This clear change supports the thesis that Google search frequencies are associated with changes in the behaviour of social groups, which in this case are mostly aimed at containing the COVID-19 contagion.

15 Activa Research (March 2020). Los Chilenos y el Coronavirus. Available at https://www.activasite.com/wpcontent/uploads/2020/03/Informe-Los-Chilenos-y-el-Coronavirus-1.pdf. Activa Research (Marzo 2020). Pulso Ciudadano. Available at https://media.elmostrador.cl/2020/03/Especial-Pulso-Ciudadano-Coronavirus-Marzo-2020.pdf

${ }^{16}$ Available at https://www.google.com/covid19/mobility/

${ }^{17}$ Google (2020). COVID-19 Community Mobility Report - Chile, March 29, 2020. Available at

https://www.gstatic.com/covid19/mobility/2020-03-29_CL_Mobility_Report_en.pdf 
Figure 6. Changes in Chile's mobility during the COVID-19 pandemic

Retail and recreation $(-73 \%)$

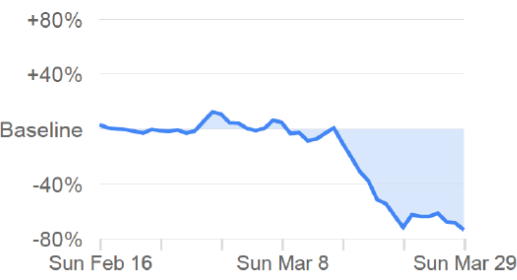

Grocery and pharmacy (-55\%)

$$
+80 \%
$$

$+40 \%$

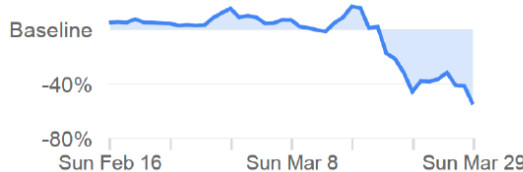

Parks $(-72 \%)$

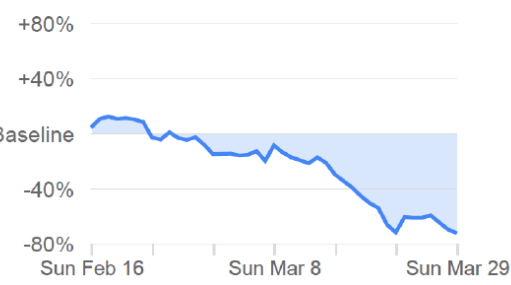

Transit stations (-64\%)

$+80 \%$

$+40 \%$

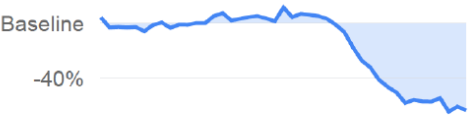

Worplaces (-42\%)

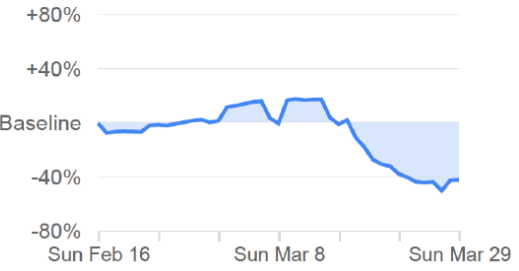

Residential (+24\%)
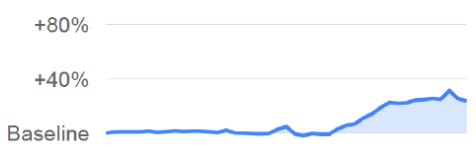

$-40 \%$

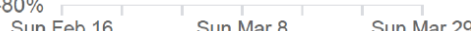

Source: Google (2020). COVID-19 Community Mobility Report - Chile, March 29, 2020

Overall, this evidence is very relevant to explain the relationship between Google searches and changing infection trends. What all these data show is that the information saturation peak (moment 2) was accompanied by three changes: a growth in citizen concern (moment 1), greater dissemination of information in the population (moment 3 ) and a generalisation of measures against the spread of the virus (moment 4). In this way, the Chilean case shows concrete evidence that allows us to justify the explanatory mechanism that we have proposed in Figure 4.

\subsection{The communicated content matters. Reviewing the Italian case}

Italy is the one case that, having reached a clear information saturation peak, has not been able to contain the virus spread yet, as the following figure illustrates.

Figure 7. Evolution of COVID-19 confirmed cases and Google searches, Italy

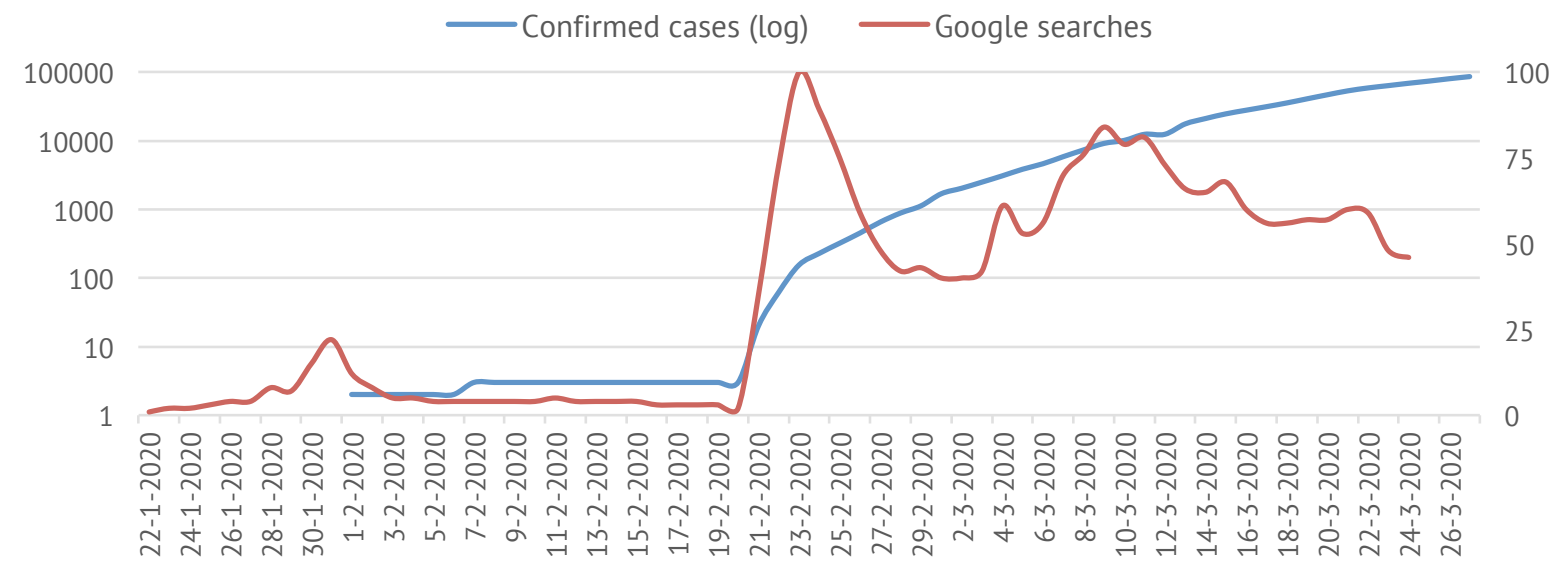

Source: authors, based on Google Trends Analytics and Coronavirus COVID-19 Global Cases by the Center for Systems Science and Engineering (CSSE) at Johns Hopkins University.

Although there were signs of moderate mitigation of the contagion - around February 24 - the change in trend was not as significant as in the recovering countries. The question, then, is why a developed country whose 
public health system is a well-prepared one ${ }^{18}$, and whose prime minister, Giuseppe Conte, took lockdown measures starting on February $23{ }^{19}$ has not reached a clear contagion downward changepoint yet?

Some have claimed that Italy's high proportion of people over 65 years-old - the second oldest population in the world after Japan's ${ }^{20}$ - is the factor that has increased contagion and death rates. Others say that the "tactile" Italian culture has made it too difficult for Italians to avoid physical contact, promoting the virus spread. Both factors could certainly be affecting this trend, but they are too stable to contribute to the understanding of rapid variations in transmission trends.

From our perspective, in societies with a high level of information dissemination, it is necessary to consider a third factor: what kind of public opinion was generated about the virus. At the time when information about the coronavirus was massively disseminated in Italy - the information saturation peak, which occurred on February 23 , the same day when the partial lockdown started - some Italian public authorities strongly underestimated the disease, and that could have slowed down an information process that might otherwise have been beneficial in containing the contagion.

To illustrate that, let us take some examples, all of which took place the same day, February $27^{21}$, only four days after Mr Conte's measures were announced. The first episode refers to Mr Nicola Zingaretti, president of the Lazio region (which comprises Rome), who posted a photo of his after-work aperitivo on February 27, implying that the disease was not that bad. He is now one of the active infected subjects. The second example is about the country's foreign minister, Luigi di Maio, who claimed: "In Italy, we went from the risk of an epidemic to an infodemic", blaming the media coverage for generating unnecessary panic among the population. Last but not least, the mayor of Milan, Giuseppe Sala, likewise launched the campaign "Italy doesn't stop, Milan doesn't stop" on February 27, reopening the famous Milanese cathedral, Il Duomo, and asserting that the lockdown measures were exaggerated.

An additionally relevant factor that has allowed the rise of the disease has been the suspension of COVID-19 testing on asymptomatic Italians ${ }^{22}$. "Test, test, test. All countries should be able to test all suspected cases, they cannot fight this pandemic blindfolded", said Tedros Adhanom Ghebreyesus, the head of the World Health Organization (WHO). To prove that testing was effective regarding disease control - which had already been noted by the South Korean experience - scientists tested the entire population of Vo (3.000 people), a town located in the region of Veneto in the North of Italy, following which transmission ceased totally.

On balance, both the halting of COVID-19 testing as well as the reckless decisions and communications of some Italian authorities might have outweighed the precautionary attitude indicated by the Google search peak of February 23. These specific factors must be considered in the explanation of the Italian case, along with the more general explanations based on demographics or cultural aspects.

\footnotetext{
${ }^{18}$ According to the Global Health Security Index (GHS), Italy is within the "More Prepared Countries" category, as well as Singapore, and above China. https://www.ghsindex.org/country/italy/

${ }^{19}$ The Economist (March 10, 2020). Italy is locked down to slow the spread of coronavirus. Available at https://www.economist.com/europe/2020/03/10/italy-is-locked-down-to-slow-the-spread-of-coronavirus

20 The Economist (March 19, 2020). The lockdown and the long haul. Available at https://www.economist.com/briefing/2020/03/19/in-europe-and-around-the-world-governments-are-getting-tougher

21 The New York Times (March 21, 2020). Italy, Pandemic's New Epicenter, Has Lessons for the World. Available at https://www.nytimes.com/2020/03/21/world/europe/italy-coronavirus-center-lessons.html

22 The Economist (March 19, 2020),. The coronavirus pandemic. Available at https://www.economist.com/science-andtechnology/2020/03/19/developing-and-deploying-tests-for-sars-cov-2-is-crucial
} 


\section{CONCLUDING REMARKS}

\subsection{Main findings}

This article has sought to evaluate the possibilities of taking Google searches as a way of studying how social groups are responding to the coronavirus and other epidemics. Even though we describe this as an exploratory study, we have found that digital traces left by Google searches could help to identify and measure citizens' attitudes. In more detail, we can highlight the following conclusions:

1. Despite the variable time lapse between the maximum volume of searches on Google and the downward changepoint of contagion, we are positive that the former precedes the latter in all cases, regardless of the cultural, political, and ethnic differences among the countries examined. Apparently, the exponential spread of the virus in the population tends to decrease between 1 and 9 days after information peak in Google, although this mitigation is not in all cases equally effective or definitive; this becomes clearer when reviewing the case of Italy.

2. This relation does not imply causality, but it suggests that there is a correlation between Google search records and the spread of this pandemic. The analysis of the Chilean case further suggests that what explains this correlation is the joint manifestation of the information saturation peak with three social phenomena: an increase in people's concern about the virus, the emergence of a more informed citizenry regarding COVID-19 symptoms and forms of containment, and a stronger response to contagion with appropriate behaviours and mobility patterns.

3. Our findings might have public policy and crisis management applications. As we showed, the information saturation peak could be taken as a proxy for citizens' concern and their response level, giving some guidance to both policy and decision-makers ${ }^{23}$. On balance, this way of measuring those phenomena is fast, accessible, low cost, and does not infringe on any privacy rights ${ }^{24}$, which is one of the main obstacles when researching these phenomena. This also raises the importance of further developing digital methods that can be useful in times of crisis - when traditional social science approaches face serious challenges.

4. Regarding crisis management effectiveness, this will not depend exclusively on the volume of information - which is fundamental - but also on the quality of it. The Italian case shows how even after the highest point of Google searches on the topic, the country did not reach a significant downward point in disease transmission - probably because of some unfortunate statements from some Italian politicians.

\subsection{Limits and challenges}

Since this is still an exploratory inquiry, there are some limitations or considerations, and we can list at least three of them:

\footnotetext{
${ }^{23}$ Presumably following similar conceptions, The Economist published on March 17, 2020, a study based on Instagram posts to track its users' travels and, from that, estimate their virus exposure. The Economist (March 17, 2020). Instagram may offer clues about the spread of the new coronavirus. Available at https://www.economist.com/graphic-detail/2020/03/17/instagram-may-offer-clues-aboutthe-spread-of-the-new-coronavirus

${ }^{24}$ We used only aggregated national and regional data. Considering that our interest was to find social or collective behaviour and attitudes trends, it is not necessary to indagate at an individual level, at which point there might be some privacy rights violations.
} 
1. When considering crisis and epidemic management, it is fundamental to understand and analyse the political components of it, as well as the content being disseminated in the information peaks. Both factors - the political management of crises and the content of communication about them - are highly linked to social responses and change very quickly in challenging times. Therefore, it would be necessary to monitor them in order to understand the role they play both in the spread of the disease and in the generation of information peaks. For example, it is necessary to review the impact that virustesting policies may have had on generating decreases in confirmed COVID-19 cases. It would also be relevant to see if information peaks have normally been preceded by political announcements, such as mass quarantines.

2. There are more structural institutional variables that we did not contemplate in this research - and that we should if taking it further - such as how well-prepared every country's health system is to prevent and react to a pandemic; how well-functioning their institutions and democracies are; how distributed the domestic economic activities are and the impact that has on the labour market, and how credible governments are in confronting the crisis. Our results so far have assumed that these elements are constant within countries, so they could not explain the downward trend changes. However, in times of deep crisis, there may be rapid institutional changes in these aspects that would need to be considered in detail.

3. Finally, in further research, we should also analyse in detail regional data and Google search terms. Doing so would enable us to establish more comprehensive and data-driven conclusions, as well as drawing more focused public policy and management crisis applications.

\section{REFERENCES}

Activa Research (March 2020). Los Chilenos y el Coronavirus. Available at https://www.activasite.com/wpcontent/uploads/2020/03/Informe-Los-Chilenos-y-el-Coronavirus-1.pdf.

Activa Research (March 2020). Pulso Ciudadano. Available at https://media.elmostrador.cl/2020/03/Especial-PulsoCiudadano-Coronavirus-Marzo-2020.pdf

Ahmed, F., Asif, R., Hina, S., \& Muzammil, M. (2017). Financial Market Prediction using Google Trends. International Journal of Advanced Computer Science and Applications, 8(7), 388-391.

Alexa Internet (2020). The Top 500 Sites on the Web. Available at https://www.alexa.com/topsites

Choi, H., \& Varian, H. (2012). Predicting the Present with Google Trends. Economic Record, 88, 2-9.

Dukic, V., Lopes, H. F., \& Polson, N. G. (2012). Tracking Epidemics with Google Flu Trends Data and a State-space SEIR Model. Journal of the American Statistical Association, 107(500), 1410-1426.

Global Health Security Index (2019). Available at https://www.ghsindex.org/country/italy/

Google (2020). COVID-19 Community Mobility Report - Chile, March 29, 2020. Available at https://www.gstatic.com/covid19/mobility/2020-03-29_CL_Mobility_Report_en.pdf

Graham, M. (2014). Internet Geographies: Data Shadows and Digital Divisions of Labour. In Society and the Internet: How Networks of Information and Communication are Changing our Lives, eds M. Graham and W. H. Dutton. Oxford: Oxford University Press. 99-116. 
Hubbard, D. W. (2011). Pulse: The New Science of Harnessing Internet Buzz to Track Threats and Opportunities. John Wiley \& Sons.

Internet Live Stats (2020). Available at https://www.Internetlivestats.com/google-search-statistics/

Johns Hopkins University Center for Systems Science and Engineering (2020). 2019 Novel Coronavirus COVID-19 (2019nCoV) Data Repository. Available at https://github.com/CSSEGISandData/COVID-19.

Killick, R., \& Eckley, I. (2014). Changepoint: An R Package for Changepoint Analysis. Journal of statistical software, 58(3), 1-19.

Killick, R., Fearnhead, P., \& Eckley, I. A. (2012). Optimal Detection of Changepoints with a Linear Computational Cost. Journal of the American Statistical Association, 107(500), 1590-1598.

Lai, C. C., Shih, T. P., Ko, W. C., Tang, H. J., \& Hsueh, P. R. (2020). Severe Acute Respiratory Syndrome Coronavirus 2 (SARS-CoV-2) and Coronavirus Disease-2019 (COVID-19): the Epidemic and the Challenges. International Journal of Antimicrobial Agents, 105924.

Lu, Y., Wang, S., Wang, J., Zhou, G., Zhang, Q., Zhou, X., ... \& Chou, K. C. (2019). An Epidemic Avian Influenza Prediction Model Based on Google Trends. Letters in Organic Chemistry, 16(4), 303-310.

Lupton, D. (2014). Digital sociology. Routledge.

Marres, N. (2017). Digital Sociology: The Reinvention of Social Research. John Wiley \& Sons.

Matta, M., Lunesu, I., \& Marchesi, M. (2015,). Bitcoin Spread Prediction Using Social and Web Search Media. In UMAP Workshops (pp. 1-10).

Miller, D. \& Slater, D. (2000). The Internet: An ethnographic Approach. Oxford: Berg. Horst, H. A., \& Miller, D. (Eds.). (2013). Digital Anthropology. A\&C Black.

Pollett, S., Boscardin, W. J., Azziz-Baumgartner, E., Tinoco, Y. O., Soto, G., Romero, C., ... \& Rutherford, G. W. (2016). Evaluating Google Flu Trends in Latin America: Important Lessons for the Next Phase of Digital Disease Detection. Clinical Infectious Diseases, Volume 64, Issue 1, 34-41.

Polykalas, S. E., Prezerakos, G. N., \& Konidaris, A. (2013, December). An Algorithm based on Google Trends' Data for Future Prediction. Case study: German Elections. In IEEE International Symposium on Signal Processing and Information Technology (pp. 69-73). IEEE.

Rieder, B, Röhle, T (2012) Digital Methods: Five Challenges. In: Berry, DM (ed.) Understanding Digital Humanities. London: Palgrave Macmillan, pp. 67-84.

Rogers, R. (2013). Digital Methods. London: MIT Press.

Stat Counter (2020). Available at https://gs.statcounter.com/search-engine-market-share

Seo, D. W., \& Shin, S. Y. (2017). Methods using social media and search queries to predict infectious disease outbreaks. Healthcare informatics research, 23(4), 343-348.

The Economist (March 10, 2020). Italy is locked down to slow the spread of coronavirus. Available at https://www.economist.com/europe/2020/03/10/italy-is-locked-down-to-slow-the-spread-of-coronavirus

The Economist (March 19, 2020). The coronavirus pandemic. Available at https://www.economist.com/science-andtechnology/2020/03/19/developing-and-deploying-tests-for-sars-cov-2-is-crucial 
The Economist (March 19, 2020). The lockdown and the long haul. Available at https://www.economist.com/briefing/2020/03/19/in-europe-and-around-the-world-governments-are-gettingtougher

The Economist (March 17, 2020). Instagram may offer clues about the spread of the new coronavirus. Available at https://www.economist.com/graphic-detail/2020/03/17/instagram-may-offer-clues-about-the-spread-of-thenew-coronavirus

The New York Times (March 21, 2020), Italy, Pandemic's New Epicenter, Has Lessons for the World. Available at https://www.nytimes.com/2020/03/21/world/europe/italy-coronavirus-center-lessons.html

Venturini, T., Bounegru, L., Gray, J., \& Rogers, R. (2018). A Reality Check (list) for Digital Methods. New Media \& Society 20(11), 4195-4217.

Wu, L., \& Brynjolfsson, E. (2015). The Future of Prediction: How Google Searches Foreshadow Housing Prices and Sales. In Economic Analysis of the Digital Economy (pp. 89-118). University of Chicago Press.

Xu, Q., Gel, Y. R., Ramirez, L. L. R., Nezafati, K., Zhang, Q., \& Tsui, K. L. (2017). Forecasting Influenza in Hong Kong with Google Search Queries and Statistical Model Fusion. PloS one, 12(5).

Yang, S., Santillana, M., Brownstein, J. S., Gray, J., Richardson, S., \& Kou, S. C. (2017). Using Electronic Health Records and Internet Search Information for Accurate Influenza Forecasting. BMC infectious diseases, 17(1), 332.

Zook, M., Dodge, M., Aoyama, Y., \& Townsend, A. (2004). New Digital Geographies: Information, Communication, and Place. In Geography and Technology (pp. 155-176). Springer, Dordrecht. 